\title{
Small-Scale Agriculture as a Panacea in Enhancing South African Rural Economies
}

\author{
*Mfaniseni Wiseman Mbathaํㅜㄹ Mfundo Mandla Masuku² \\ ${ }^{1}$ University of Zululand, South Africa \\ ${ }^{2}$ North West University, South Africa \\ Wisemanmbatha11@yahoo.com
}

\begin{abstract}
The small-scale agricultural sector is considered as an indispensable role player in improving the South African rural economies by means of enhancing sustainable rural livelihoods. This paper critically assesses the contribution of small-scale agriculture in enhancing the South African rural economies. The South African Government have numerous agricultural interventions as an approach to improving rural livelihoods. Despite various policies and interventions that have been in place to ensure that small-scale agriculture improves rural economies; there is still a dearth of research in understanding small-scale agriculture dynamics that affect rural economies. Some of the essential aspects of the findings reveal that rural communities in South Africa regard small-scale agriculture as a source of income generation and enhancing food security. These findings highlight the negative effects on the South African small-scale agriculture suffering from insufficient productivity, infertility of soil, insufficient water and climate change. The poor access to markets and inadequate financial support services were identified as the major constraints that hinder small-scale agriculture to contribute to the Gross Domestic Product (GDP) and rural economic development. The small-scale agricultural sector should come up with self-sufficient interventions to avoid dependence on the Government and other stakeholders.
\end{abstract}

Keywords: Climate Change, Rural Communities, Rural Economy, Small-Scale Agriculture, South Africa

\section{Introduction}

The agricultural sector is regarded as the main driver for rural economic development (Gomala \& Baluchamy, 2018) an essential asset and primary source of income at a household level and in developing countries with more than $69 \%$ of poor people in the world making a living in rural areas. USAID (2018) acknowledges that almost $70 \%$ of Southern African rural communities depend on the agricultural sector to secure their livelihoods. The South African Government regards the participation of rural communities in the agricultural sector as a pivotal strategy to improve rural economies. In South African rural areas, small-scale agriculture is characterised by the production in both crop and livestock farming systems where rural farmers work in groups on a small portion of land (Lininger, 2011) intended to meet their household necessities (Mthembu, 2013). Due to the insufficient production in the South African agricultural sector and the lack of productivity in rural farming systems identified by Lahiff \& Cousins (2005); the South African rural economy is threatened by inadequate economic activities that have resulted in restrictions in creating rural economic growth. Smallscale agriculture intends to make a significant contribution to improving rural economies by way of creating employment opportunities, provision of food and contributing to the Gross Domestic Product (GDP). Lehohla (2016) state that there is a decline in rural agriculture since the estimated percentage shows only $13.8 \%$ of South African rural households are still engaged in the agricultural sector as compared to $19.9 \%$ in 2011 .

Small-scale agriculture is therefore vulnerable in contributing to rural economic development because of the inadequate formal and informal infrastructure, poor market and low productivity of farming systems (Mthembu, 2013). Sekaleli \& Sebusi (2013), stress that the agricultural sector, which mostly depends on rainfall is experiencing tragic failure in productivity caused by the impact of climate conditions. Therefore, it has become critical to assess the contribution of small-scale agriculture towards enhancing South African rural economies. This paper seeks to address two main objectives the first is to determine the role of smallscale agriculture in enhancing rural economy; and to identify the challenges hindering small-scale agriculture to enhance rural economies. There are vast studies that have been undertaken to validate the role played by agriculture in spearheading rural communities in South Africa, included those by Van Zyl, Nel \& Groenewald (1988); Sihlobo \& Nel (2016) and; Pfunzo (2017). However, there have been limited studies undertaken to discuss the contribution of small-scale agriculture to rural economies in South Africa. The findings of this paper will contribute to the body of knowledge by signifying the importance of prioritising small-scale agriculture towards ensuring effective improvement in rural economies. The information retrieved from this 
paper plays a vital role to comprehend the value of small-scale agriculture in improving rural economies. The South African small-scale agricultural sector faces the danger of climate change of drought negatively impacting.

\section{Literature Review}

The contribution of both subsistence and small-scale agriculture in improving the rural economy is not well studied in South Africa. Kleinbooi (2010) suggested the need to review the procedures used in exploring studies researching small-scale agriculture to ensure it accurately records the role of small-scale agriculture and its potential in contributing to rural economic development. The contribution of small-agriculture in the South African rural economy is not well recognised or documented because there is a dearth of environmental policies supporting and protecting rural farmers from all possible risks they may face (Khwidzhili \& Worth, 2017). This has resulted in negative outcomes on the role of small-scale agriculture in accessing the market and its contribution to the GDP to enhance the rural economy. This section reviews literature that is related to the small-scale agriculture and its contribution to rural economies.

General Overview on Small-Scale Agriculture in South Africa: Small-scale agriculture is described as a sector where rural communities apply their indigenous knowledge for farming to ensure that their farms are productive (Simelane, 2017). South African small-scale agriculture is characterised by the production in a dualistic farming system, which includes both crop and livestock farming (Lininger, 2011). The integration of both crop and livestock farming has turned out to be very low in terms of productivity and has a negative impact on the contribution of small-scale agriculture in improving rural economies (Siegmund-Schultze et al., 2013). Small-scale agriculture is a process of transforming subsistence agriculture to commercial agriculture with the purpose of selling their products to the market and ensuring the availability of food in their households (Tagar \& Shah, 2012). Small-scale agriculture is a major contribution to ensuring food security, creating employment opportunities and reducing poverty in rural households worldwide. Mthembu (2013) state that $92 \%$ of rural households engage in agriculture with the purpose of producing food and small-scale agriculture creating employment opportunities for almost four million of the Country's population.

Households participate in small-scale agriculture with the purpose of generating income in order to supplement their household expenses. These two incentives have turned out to be a proposition that plays a crucial role in supporting and motivating rural farmers to engage in small-scale agriculture and towards improving the standard of living in rural communities (Aliber, 2011). South Africa is reported to have an adequate production of food more especially at the national sphere (Baiphethi \& Jacobs, 2009). Regardless of small-scale agriculture contributing to both food and income, it is also expected to contribute to the Country's GDP making sure there is an improvement in rural economies. Small-scale agriculture is struggling to contribute to the rural economy since rural communities participate in unstable rural based markets whereby they sell their product to other residents and neighbours. It is estimated that the agricultural sector contributes less than 3\% in the GDP while contributing 7.2\% towards formal employment. On the other hand, the Department of Agriculture, Forestry and Fisheries (2017) indicated that in South Africa, the agricultural sector was estimated to have the production value of R 273333 million and it contributed almost R 80245 million in 2016.

Challenges that Hinders Small-Scale Agriculture to Contribute in Rural Economy: The South African small-scale agricultural sector is currently suffering from the consequences of climate change crippling productivity of the agricultural sector (Mthembu, 2008). Ren et al. (2018) agreed that climate change conditions have a negative effect on the agricultural sector worldwide, with a tragic decline in agricultural production due to the number of incidences of natural disasters. The incidence of drought has led to the scarcity of water for irrigation during the dry seasons creating a struggle in small-scale agriculture to produce sufficient product to be sold in the market. Rowhani et al. (2011) state that climate change brings many fluctuations in the production of the country's agricultural sector and in turn an obstacle in the contribution of small-scale agriculture in rural economies. On the other hand, Chikazunga \& Paradza (2012) perceived that small-scale agriculture has little to offer in rural economies because of the unavailability of financial support system in order to assist poor rural farmers. Hanf (2014), identified that the neglect of rural small-scale agriculture by the South African Government which focuses more on supporting the commercial agricultural 
sector. Small-scale farmers become vulnerable with no financial support to purchase fertilizers and feeding resources to assist in keeping the farming sector more productive. Greenberg (2013) state that small-scale farmers experience these problems because the Government provides more support for the large-scale farming sector, aiming to adapt to the competition that takes place in a global level. Van Rooyen et al. (2017) agreed to most countries governments and benefactors focus more on assisting large-scale farmers by paying for infrastructural services.

\section{Methodology and Materials}

Data Collection and Analysis: The case study research was adopted in order to collect secondary data that is relevant to the small-scale agriculture and rural economy. This paper relied on secondary data to analyse the contribution of the small-scale agricultural sector in enhancing the rural economy. The case study played a significant role in understanding previous and the complex issues hindering the contribution of small-scale agriculture in rural economies. Zainal (2007) state that the case study method enabled researchers to reach the further side of the quantitative statistics results. Case studies help a researcher to include both quantitative and qualitative data in explaining the process and outcome of the phenomenon by the full reconstruction and analysis of cases that are under investigation. The case study helps researchers to collect the relevant information from different sources including officially published materials, technical reports and documentation of data collection methods and procedures (Johnston, 2017). For the purpose of data analyses, this paper adopted textual analysis as a tool to analyse reviewed literature, relevant to the small-scale agriculture and its contribution to rural economies.

Theoretical Framework: The modernisation of agriculture through the modernisation theory was adopted because of its strength and positive orientation to enable poor rural people to be part of the social and economic development. Modernisation theory is often used to provide a full explanation of the processes of agricultural transformation within societies. Power (2004) referred to the modernisation process to a model of bringing transformation from the traditional societies to modern societies. Concerning the agricultural sector, modernisation theory promotes a shift away from practising traditional agricultural methods to adopting modern methods of agricultural practice. Toringepi (2016) mention that the modernisation theory gave the small-scale farmers an option to substitute traditional agricultural methods (such as depending on rainfall, hand digging, shift cultivation), with modern agricultural methods (such as utilisation of advanced machines and fertilisers). Power (2004) further clarified that this theory focused on the principles, which states there is a strong connection between the social and economic development towards bringing significant progress and improvement in human development. The modernisation theory encourages the adoption of technological process in order to assist rural communities to have control over their farming systems. The adaptation of technological advancement is pivotal in the background of this paper since smallscale agriculture currently linked with an underprivileged level of technology (Toringepi, 2016).

If small-scale agriculture can be granted the opportunity to be modernised, they can contribute to the economic development of rural communities. Barnett et al. (1995) modernisation phenomenon include a full range of changes and transformation which all traditional societies have to follow to reach the level of being modernised. The process of modernisation in small-scale agriculture encompasses guidance and motivation for farmers to start using new production, crops and try new marketing skills. Toringepi (2016) claim that modernisation of the agricultural sector introduced to the diversification of farming systems, utilisation of chemical fertilisers, tractors and the adoption of different scientific knowledge to replace traditional agricultural methods. Small-scale agriculture should be regarded as modern once farmers show some specific features. These features include being able to take effective decisions, having high technological skills and understanding the value of production (Toringepi, 2016). There are challenges faced by small-scale agriculture in most developing countries including inadequate scientific knowledge, lack of equipment and scant marketing skills. Previous research of the model revealed that governments in most developing countries do not focus on the role of small-scale agriculture in addressing rural issues ensuring rural economic development (Lewis, 2013). 


\section{Results and Discussion}

The Nature of Agricultural Sector in South Africa: The results show that South Africa has two categories of agriculture. It is subsistence agriculture, usually practised by rural farmers; and large-scale agriculture, mainly practised by white people for commercial purposes. Tagar \& Shah (2012) point out that small-scale agriculture is to transform subsistence agriculture to commercial agriculture by enabling rural communities to improve the rural economy and sustainable livelihoods. Despite the important role of small-scale agriculture in South African rural economies, studies have shown that there are insufficient details and reliable empirical evidence about the existence and operation of small-scale agriculture in rural areas. This includes the shortage of recorded data about the trades, value and volume production of small-scale agriculture in South Africa (Lahiff \& Cousins, 2005; Ngcoya \& Kumarakulasingam, 2017). Based on the aforementioned circumstances, data pertaining to agriculture is being collected through community surveys by Statistics South Africa, with the intention of understanding the nature of small-scale agricultural practice at the level of households in South Africa. Figure 1, clearly displays the percentage of household participation in the South African agricultural sector in 2016.

Figure 1: Percentage of Household Participation in South African Agricultural Sector in 2016

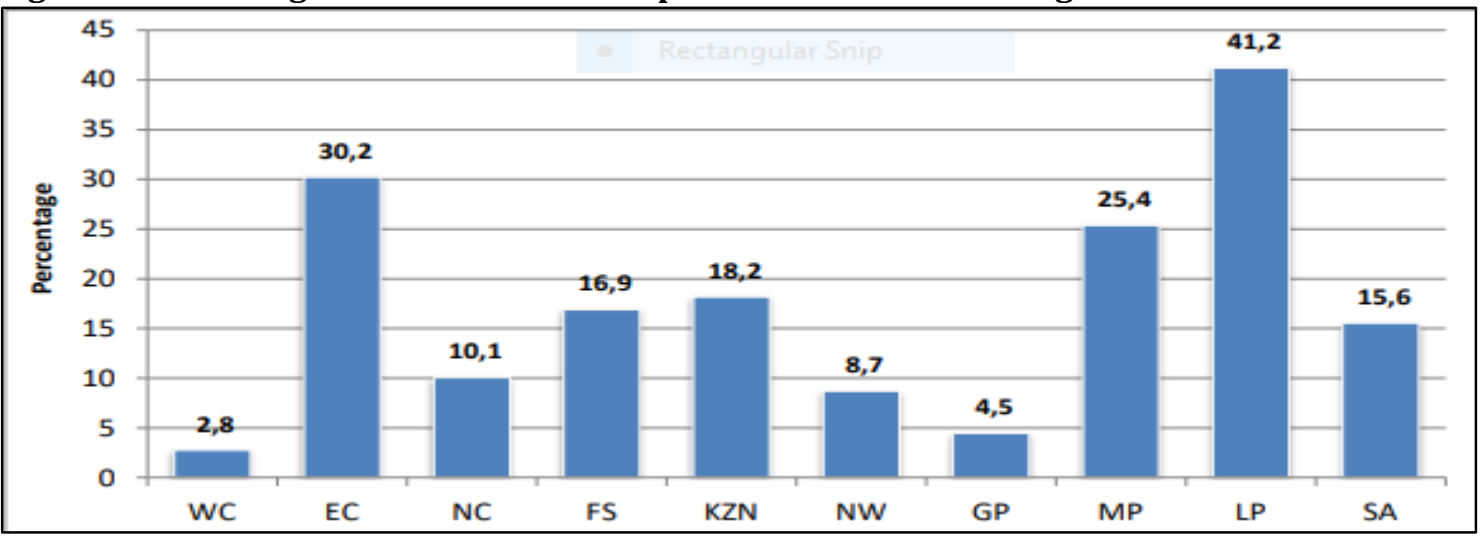

Source: Statistics South Africa, 2017.

Figure 1 showed that in 2016, 15.6\% of South African households were engaged in agricultural activities with an increase of $0.8 \%$ as compared to $14.8 \%$ in 2015 . It has been recognised that $9.9 \%$ of these households have cultivated farmlands, whilst $92.7 \%$ were engaged on small-scale farming (Statistics SA, 2017) including backyard gardens. The small-scale agriculture was dominated by the dualistic farming system, which includes both crop and livestock farming in some rural areas in South Africa. Statistics South Africa (2017) showed that the South African household from their small-scale agriculture produced 53.4\% of crops (both fruits and vegetables) and $47.1 \%$ of livestock in 2016. In 2016, only $11.1 \%$ of agricultural households have received support from the Government to improve their small-scale agriculture. In contrast, only $2.2 \%$ of those households who have received assistance through training and $7.0 \%$ received assistance pertaining to livestock vaccination services (Statistic South Africa, 2017).

Reasons for Small-Scale Agriculture in South African Rural Areas: Aliber (2011) agreed that the percentage in the productivity of livestock and crops as mentioned above have turned out to be a proposition that plays a crucial role in motivating rural farmers to participate in small-scale agriculture toward improving the standard of living in their communities. Therefore, small-scale agriculture (see Figure 2) can be mainly observed as both a source of income and food in South Africa. 
Figure 2: Reasons for Engaging on Small-Scale Agriculture in South Africa

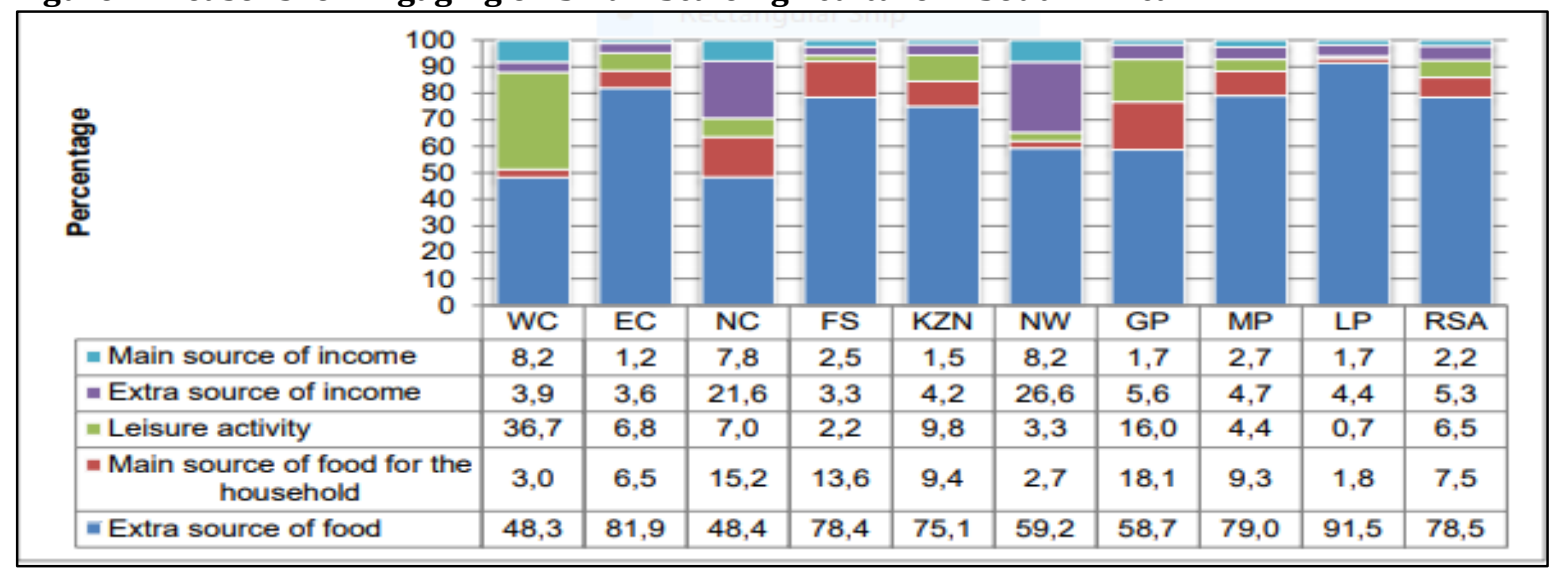

Source: Statistics South Africa, 2017

Small-Scale Agriculture as a Source of Food for Rural Communities: Figure 2 shows that almost $78.5 \%$ of South African households engage in agriculture to secure an additional source of food and income. Households engaging in small-scale agriculture as an additional source of food, more especially in rural areas can be seen as a motivating factor in the following provinces: Limpopo Province at $91.5 \%$; Eastern Cape Province with 81.9\%; and Mpumalanga Province with 79.0\%. Baiphethi \& Jacobs (2009) found that in South Africa, the issue of food insecurity has an impact on poor individuals who reside in urban areas. They are dependent on accessing food from markets, which is different from the rural context where people directly engage in subsistence and small-scale agriculture to ensure the availability of food and generating a source of income. Ruel et al., (1998); and Baiphethi \& Jacobs (2009) note a severe increment on the reliance of rural and urban area households in purchasing food from the market. The expenditures on purchasing food from the markets can be estimated to be almost $60-80 \%$ which is made up by the total income of households dominated by individuals with low income from urban areas.

Small-Scale Agriculture as a Source of Income for Rural Communities: The availability of employment opportunities for rural communities in small-scale agriculture could determine the sustainable generation of income for rural populace. Aref (2011) affirm that small-scale agriculture has made a significant contribution in generating income for rural households. The South African agricultural sector is currently unable to effectively contribute in the creation of job opportunities, following a decline of about $0.3 \%$ in agricultural employment opportunities during the first quarter of 2018 from $4.8 \%$ of the fourth quarter in 2017 (Statistic SA, 2018). In 2016, South African rural households experienced a huge decline in agricultural productivity (Lehohla, 2016). Figure 2 depicts two of the nine South African provinces North West (26.6\%) and Northern Cape $(21.6 \%)$ regard small-scale agriculture as an extra source of income. The contribution of small-scale agriculture in household income is too low compared to that of food per households. In the first quarter of 2018, Statistics South Africa (2018) indicate that only $5.3 \%$ of South African households engage in agriculture as an extra source of income while $2.2 \%$ view it as a main source of income.

Challenges that Hinders Small-Scale Agriculture to Contribute in Rural Economy: Ikerd (2011) assert that small-scale agriculture must be able to protect the productivity of land and enhance the rural economy. The productivity of small-scale agriculture is facing challenges which constraint farmers' from benefiting from their farming activities in rural areas. The small-scale agriculture is currently struggling to enhance rural economies due to the following challenges:

Issues of Climate Change: It has been recognised that the entire agricultural sector is in serious jeopardy due to the circumstances of climate change conditions (Ojoyi et al., 2017). Small-scale agriculture in South African rural areas become more vulnerable to climate change conditions since they depend more on rainfall during the summer season. The effects of climate change have put rural economies in danger with the lack of water and food availability. Following the drought experience between the 2015 and 2016 the Country due to climate change has affected the productivity of small-scale agriculture in South Africa, see Figure 3 below. 
Figure 3: Showing Drought Conditions in South Africa (2015-2016)

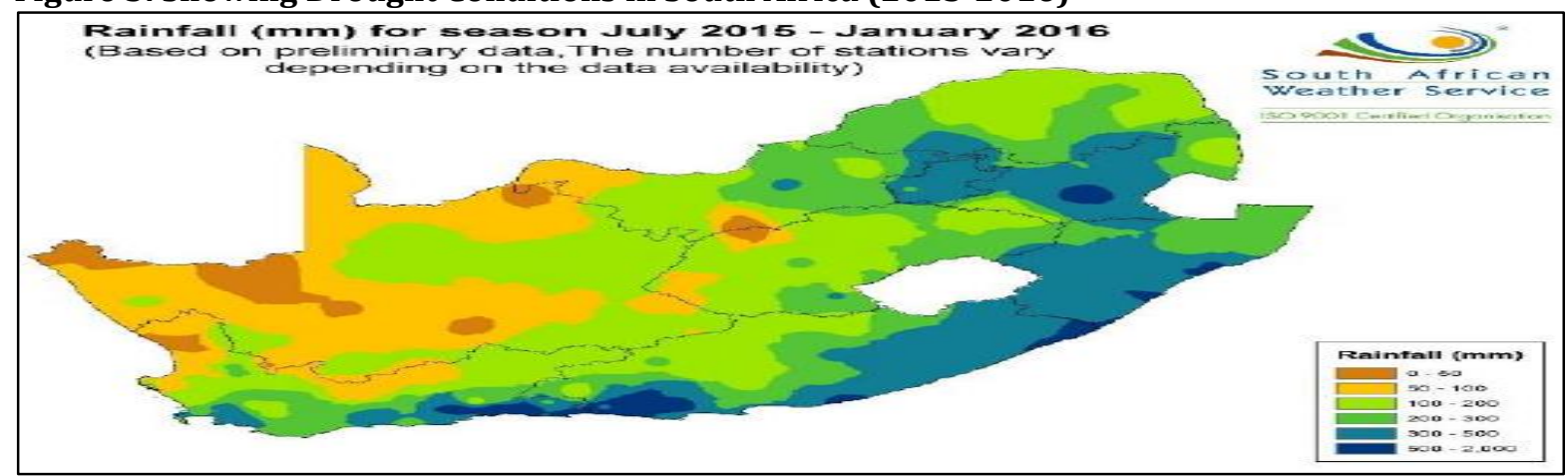

Source: Lehohla, 2016

The incidence of drought as it appears in Figure 3, negatively led to water scarcity leaving small-scale agriculture with no water for irrigation, especially during winter. Hristov et al. (2018) point out that productivity in livestock and crop systems are vulnerable because of climate change. Small-scale agriculture is an essential instrument in improving the rural economy, it is important that it remains productive even during the times of climate change so that it will manage to contribute in enhancing the rural livelihoods and economies. Ren et al. (2018) suggested that rural farmers create strategies to adapt to climate change circumstances by keeping small-scale agriculture productive and the ability to improve their economies.

Inadequate Infrastructural Services and Access to the Markets: Khandker \& Samad (2018) identified prioritising investment in rural infrastructural facilities (such as irrigation systems, roads, telecommunications and so forth) could have an appropriate impact on small-scale agriculture enhancing rural economies. Simelane (2017) point out that small-scale farmers may have insufficient experience in technology to sustain their agricultural activities and accessing major markets. Infrastructural service in the South African rural areas remains a serious problem as the majority of small-scale farmers lack transport to access the markets and irrigation systems to facilitate their farms. The markets play an essential role in improving rural economies, since most South African farmers have a desire to sell their products to the market (Kapungu, 2013). The small-scale agricultural sector is still unable to gain access to the markets due to poor transport systems not catering to agricultural produce or production. This issue has been a persisting challenge in most South African rural areas where small-scale farmers use inappropriate transport to supply their product to the markets (Bourguignon \& Pleskovic, 2008; Mthembu, 2008).

Transport services (such as roads) have an essential role to play in linking rural farmers with the market and circulating information when telecommunications are not available. The lack of transport services is still an issue that many rural areas across the globe experience. The lack of irrigation systems was also recognised as a hindrance for small-scale agriculture to be sustainable and contribute to rural economies. Antunes et al. (2017) regarded the irrigation system as the main activity necessary in making assurances that small-scale agriculture is sustainable and solidifying the existence of the environmental system for small-scale farmers to continue participating in their activities (Antunes et al., 2017). These activities involve livestock and cropping systems that rely more on rainfall for its survival. Mosha (2018) identified rural areas where the farmers experience the absence and inadequate irrigation systems used to sustain the productivity of their small-scale agricultural sector. Small-scale farmers cannot afford to buy irrigation facilities due to the lack of financial support.

Inadequate Financial Support Service: The growth and contribution of small-scale agriculture in improving the standard of livelihoods and rural economies rely on the accessibility of financial support. The process of sustaining and transportation of products to the markets requires sufficient funds. The sad reality is that the small-scale agricultural sector still experiences the draughtiness in terms of financial support for rural farmers (Ruete, 2015) through the non-existence of policies introduced by Government to cater directly for rural farmers in the expansion of banking services through formal stakeholders and financial institutions. In South Africa, the main focus of Government is not on small-scale farmers but large-scale farmers, since 
Government does not manage to compensate for infrastructural facilities for rural farmers to access the markets. This situation leaves small-scale farmers unable to purchase enough feeding and fertiliser resources to cultivate their farms (Siegmund-Schultze et al., 2013).

\section{Conclusion}

This paper determined the role of small-scale agriculture in enhancing rural economies whilst pondering the challenges in doing so. In this regard, the findings have shown that the South African small-scale agriculture is dominated by crop and livestock activities in rural areas. Therefore, small-scale agriculture has reported to be struggling to play a significant role in improving rural economies and livelihoods. The challenges that faced the small-scale agriculture include climate change conditions and insufficient support services from Government which is crippling the sustainability of rural livelihoods and rural economy. The poor infrastructural facilities in rural areas have shown to be a disadvantage to rural farmers since they are unable to access the market and compete with the commercial farming sector. This is due to the lack of financial support services to assist rural farmers, with the results indicating that Government puts more focus on the large-scale farmers while farmers in rural areas are unable to meet the needs and demand of the markets.

Recommendations: The paper proposes the following recommendations to address the issues that hinder the contribution of small-scale agriculture in enhancing the South African rural economy:

Establishment of Rural Based Markets: The access to markets has been reported to be a problem hindering small-scale agriculture to contribute to rural economic development. Therefore, it is recommended that the South African Government should develop interventions for the small-scale agricultural sector to build rural based markets that would be a centre of connection between rural farmers and the market. This includes the advancement of technology such as online marketing strategies. It is also recommended to strengthen the rural-based market by investing in research and development to ensure the sustainability of rural livelihoods and the improvement of rural development.

Climate Change Adaptation Strategy: Climate change is a serious threat to the productivity and contribution of small-scale agriculture in improving rural economies. It is essential to bring some diversification in managing the small-scale agricultural practice. This includes a rotation in planting periods and density and processes in cultivation strategies, which would play a significant role in acting against the results of restricted moisture in order to reduce and neutralise climate change conditions. The conservation of different types of seeds that would protect the environmental diversity from danger and grant small-scale farmers with a prospect to make well-informed adoption strategies, that could be utilised towards fighting against the climate change conditions and enhancing rural economic development.

Strengthen Financial Support: The inadequate financial support services have proved to be an issue in the contribution of small-scale agriculture in rural economies. It is recommended that public or private sectors intervene in order to implement formal financial institutions which will play a significant role in the expansion of banking services in favour of rural communities. This initiative will play an important role as small-scale farmers will be able even to borrow money (loans) to purchase needed products (fertilizers, feeding resources, transport, irrigation facilities) required to sustain the productivity of their farms.

\section{References}

Aliber, M. (2011). Strategies to support South African smallholders as a contribution to government's second economy strategy: Case studies.

Antunes, P., Santos, R., Cosme, I., Osann, A., Calera, A., De Ketelaere, D., Spiteri, A., Mejuto, M. F., Andreu, J., Momblanch, A. \& Nino, P. (2017). A holistic framework to assess the sustainability of irrigated agricultural systems. Cogent Food \& Agriculture, 3(1), 1-25.

Aref, F. (2011). Farmers' participation in agricultural development: The case of Fars province, Iran. Indian Journal of Science and Technology, 4(2), 155-158.

Baiphethi, M. N. \& Jacobs, P. T (2009). The contribution of subsistence farming to food security in South Africa. Agrekon, 48(4), 459-482. 
Barnett, V., Payne, R. \& Steiner, R. (1995). Agricultural sustainability: Economic, environmental and statistical considerations. John Wiley and Sons, pp 1- 278.

Bourguignon, F. \& Pleskovic, B. (2008). Annual World Bank Conference on Development Economics-Global 2007: Rethinking Infrastructure for Development. $1^{\text {st }}$ ed. [pdf] Washington: World Bank.

Chikazunga, D. \& Paradza, G. (2012). Can smallholder farmers find a home in South Africa's food-system? Lessons from Limpopo Province.

Department of Agriculture Forestry. \& Fisheries. (2017). Economic Review of the South African Agriculture 2016/17. South Africa. DAFF.

Filtane, M. L. (2016). Parliament address on the impact of SA's drought on the agricultural economy. Agriculture, Forestry and Fisheries. United Democratic Movement (UDM).

Gomala, T. B. \& Baluchamy, S. (2018). Impact of socioeconomic conditions of Dalit women with respect to rural areas in Dindigul district of Tamil Nadu. International Journal of Research in Humanities, Arts and Science, 2(3), 21-25.

Greenberg, S. (2013). The disjunctures of land and agricultural reform in South Africa: Implications for the agri-food system. Working Paper 26. Institute for Poverty, Land and Agrarian Studies, University of the Western Cape: Bellville, South Africa.

Hanf, J. H. (2014). Processor driven integration of small-scale farmers into value chains in Eastern Europe and Central Asia: A synthesis paper. [Pdf] Europe and Central Asia: FAO of the United Nations. http://www.fao.org/3/a-au847e.pdf [Accessed 23 July 2018]

Hristov, A. N., Degaetano, A. T., Rotz, C. A., Hoberg, E., Skinner, R. H., Felix, T., Li, H., Patterson, P. H., Roth, G., Hall, M. \& Ott, T. L. (2018). Climate change effects on livestock in the Northeast US and strategies for adaptation. Climatic Change, 146(1-2), 33-45.

Ikerd, J. (2011). Economics of sustainable farming. In Proceedings of the 19th Annual Grazing Conference. [pdf] United State of America.

Johnston, M. P. (2017). Secondary data analysis: A method of which the time has come. Qualitative and Quantitative Methods in Libraries, 3(3), 619-626.

Kapungu, S. T. (2013). A study of rural women farmers' access to markets in Chirumanzu. PhD. Stellenbosch University. http://scholar.sun.ac.za/handle/10019.1/80238 [Accessed 01 July 2018]

Khandker, S. R. \& Samad, H. A. (2018). Bangladesh's Structural Transformation: The Role of Infrastructure. In Economic and Social Development of Bangladesh. $1^{\text {st }}$ ed. [ebook] Palgrave Macmillan: Cham, pp. 7192.

Khwidzhili, R. H. \& Worth, S. H. (2017). Evaluation of policies promoting sustainable agriculture in South Africa. South African Journal of Agricultural Extension, 45(2), 73-85.

Kleinbooi, K. (2010). Review of land reforms in southern Africa 2010. [pdf] $1^{\text {st }}$ ed. Bellville, Cape Town: Institute for Poverty, Land and Agrarian Studies (PLAAS).

Lahiff, E. \& Cousins, B. (2005). Smallholder agriculture and land reform in South Africa. IDS Bulletin, 36(2), 127-131.

Lehohla, P. (2016). Community Survey 2016: Agricultural households. Statistics South African.

Lewis, W. A. (2013). The Principles of Economic Planning: A study prepared for the Fabian Society. London and New York: Routledge.

Lininger, K. (2011). Small-scale farming and shifting cultivation. The root of the problem what's driving tropical deforestation today? [pdf] Cambridge.

Mosha, D. B., Vedeld, P., Katani, J. Z., Kajembe, G. C. \& Tarimo, A. K. (2018). Contribution of Paddy Production to Household Income in Farmer-Managed Irrigation Scheme Communities in Iringa Rural and Kilombero Districts, Tanzania. Journal of Agricultural Studies, 6(2), 100-122.

Mthembu, N. (2008). Perceptions of barriers to market participation among three farmer groups in rural KwaZulu-Natal.

Mthembu, N. N. (2013). Exploring characteristics of farming systems in former labour tenant communities: the case of Ncunjane and Nkaseni in Msinga. Master's thesis. University of the Western Cape, South Africa. http://etd.uwc.ac.za/handle/11394/4267 [Accessed 28 July 2018]

Ngcoya, M. \& Kumarakulasingam, N. (2017). The Lived Experience of Food Sovereignty: Gender, Indigenous Crops and Small-Scale Farming in Mtubatuba, South Africa. Journal of Agrarian Change, 17(3), 480496.

Ojoyi, M., Mutanga, O., Kahinda, J. M., Odindi, J. \& Abdel-Rahman, E. M. (2017). Scenario-based approach in dealing with climate change impacts in Central Tanzania. Futures, 85, 30-41. 
Pfunzo, R. (2017). Agriculture's contribution to economic growth and development in rural Limpopo Province: a SAM multiplier analysis. Doctoral dissertation. Stellenbosch University, South Africa. http://scholar.sun.ac.za/handle/10019.1/101160 [Accessed 02 July 2018]

Power, M. (2004). Rethinking Development Geographies. $1^{\text {st }}$ ed. London: Routledge.

Ren, X., Weitzel, M., O’Neill, B. C., Lawrence, P., Meiyappan, P., Levis, S., Balistreri, E. J. \& Dalton, M. (2018). Avoided economic impacts of climate change on agriculture: integrating a land surface model (CLM) with a global economic model (iPETS). Climatic Change, 146(3-4), 517-531.

Rowhani, P., Lobell, D. B., Linderman, M. \& Ramankutty, N. (2011). Climate variability and crop production in Tanzania. Agricultural and Forest Meteorology, 151(4), 449- 460.

Ruel, M. T., Garrett, J. L., Morris, S. S., Maxwell, D., Oshaug, A., Engle, P., Menon, P., Slack, A. \& Haddad, L. (1998). Urban challenges to food and nutrition security: a review of food security, health, and caregiving in the cities. [pdf] Washington, DC: International Food Policy Research Institute.

Ruete, M. (2015). Financing for Agriculture: How to boost opportunities in developing countries: Investment in Agriculture, Policy Brief \#3 [pdf] Canada: International Institute for Sustainable Development.

Sekaleli, T. S. T. \& Sebusi, K. (2013). Farmers' Response and Adaptation Strategies to Climate Change in Mafeteng District, Lesotho. [pdf] Lesotho: African Technology Policy Studies Network.

Siegmund-Schultze, M., Rischkowsky, B., Yuldashev, I., Abdalniyazov, B. \& Lamers, J. P. A. (2013). The emerging small-scale cattle farming sector in Uzbekistan: Highly integrated with crop production but suffering from low productivity. Journal of arid environments, 98, 93-104.

Sihlobo, W. \& Nel, L. (2016). Is South Africa's agricultural sector addressing inclusive socio-economic development? Opportunity for Change, 68, 65-81.

Simelane, N. D. (2017). The role of small-scale agriculture in poverty reduction in Cezwana area Jozini Local Municipality (KZ 272). Doctoral dissertation.

Statistics South Africa. (2017). General Household Survey 2017. Stats SA. https://www.statssa.gov.za/publications/P0318/P03182016.pdf [Accessed 29 June 2018]

Statistics South Africa. (2018). Quarterly Labour Force Survey Quarter 1: 2018. Stats SA. http://www.statssa.gov.za/?p=11139 [Accessed 29 June 2018]

Tagar, H. K. \& Shah, S. R. A. (2012). Agricultural Development: Meanings, Modes and Models (A Feasible Model for Sindh-Pakistan). International Journal of Innovative Research and Development, 1(8), 54-75.

Toringepi, G. (2016). The contribution of smallholder agriculture production to food security in rural Zimbabwe: A Case Study of Masvingo Province. Doctoral Dissertation. University of Fort Hare, South Africa.

USAID. (2018). Agriculture and Food Security. [online] United States Agency for International Development (USAID): Southern Africa Regional. https://www.usaid.gov/southern-africa-regional/agricultureand-food-security. [Accessed 11 July 2018]

van Rooyen, A. F., Ramshaw, P., Moyo, M., Stirzaker, R. \& Bjornlund, H. (2017). Theory and application of agricultural innovation platforms for improved irrigation scheme management in Southern Africa. International Journal of Water Resources Development, 33(5), 804- 823.

Van Zyl, J., Nel, H. J. G. \& Groenewald, J. A. (1988). Agriculture's contribution to the South African economy. Agrekon, 27(2), 1- 9.

Zainal, Z. (2007). Case study as a research method. Jurnal Kemanusiaan, 9, 1- 6. 